\title{
A Comparison of Energy Recovery by PATs against Direct Variable Speed Pumping in Water Distribution Networks
}

\author{
Maria Cristina Morani ${ }^{1, *}$, Armando Carravetta ${ }^{1}$, Giuseppe Del Giudice ${ }^{1}$, Aonghus McNabola ${ }^{2}$ \\ and Oreste Fecarotta ${ }^{1}$ \\ 1 Department of Civil, Architectural and Environmental Engineering (DICEA) of University of Naples \\ “Federico II", 80125 Napoli, Italia; arcarrav@unina.it (A.C.); delgiudi@unina.it (G.D.G.); \\ oreste.fecarotta@unina.it (O.F.) \\ 2 Department of Civil, Structural \& Environmental Engineering, Trinity College Dublin, Dublin 2, Ireland; \\ amcnabol@tcd.ie \\ * Correspondence: m.morani@studenti.unina.it; Tel.: +39-081-768-34-53
}

Received: 8 March 2018; Accepted: 30 May 2018; Published: 7 June 2018

\begin{abstract}
Water systems are usually considered low efficiency systems, due to the large amount of energy that is lost by water leakage and dissipated by pressure reducing valves to control the leakage itself. In water distribution networks, water is often pumped from the source to an elevated tank or reservoir and then supplied to the users. A large energy recovery can be realized by the installation of energy production devices (EPDs) to exploit the excess of pressure that would be dissipated by regulation valves. The feasibility of such a sustainable strategy depends on the potential of energy savings and the amount of energy embedded in water streams, assessed by means of efficiency measures. Alternatively, energy savings can be pursued if the water is directly pumped to the network, bypassing the elevated reservoir. This study focuses on the comparison of two solutions to supply a real network, assessed as a case study. The first solution consists of water pumping to a reservoir, located upstream of the network; the excess of energy is saved by the employment of a pump as turbine (PAT). The second scenario is characterized by a smaller pressure head since a direct variable speed pumping is performed, bypassing the reservoir. The comparison has been carried out in terms of required energy, assessed by means of a new energy index and two literature efficiency indices. Furthermore, differing design conditions have been analyzed by varying the pumping head of both the scenarios, corresponding to different distances and elevation of the water source.
\end{abstract}

Keywords: energy efficiency; energy recovery in water systems; pump as turbines (PATs); variable operating strategy; water distribution networks; water leakage

\section{Introduction}

Since the industrial revolution, population growth has been responsible for a significant increase in energy consumption. Large energy consumers include the water supply sector, whose energy consumption represents $7 \%$ of worldwide consumption, and of which the distribution of water in pipe networks accounts for approximately 2-3\% [1]. Energy consumption worldwide has increased by up to $600 \%$ over the last century [2]. Therefore, the need for sustainable growth has been a topic of paramount importance.

Sustainable growth can result in important economic and environmental advantages. Colombo and Karney [3] assert that energy consumption for water pumping is the main portion of the supply operating costs; furthermore, regarding the environmental aspects, potential energy savings in 
pumping can contribute to the reduction of acid rain and greenhouse gases emissions, in particular, $\mathrm{CO}_{2}[4-6]$.

Moreover, sustainable growth can be achieved by the development of several strategies aimed to guarantee hydraulic and energy efficiency, such as: pressure management for reduction of water losses due to leakage [7-9]; pipe repair, improvement, or replacement to reduce the problem of water leakage and thus to save the embedded energy [10-13]; and energy recovery using microturbines [2]. In particular, energy recovery is of considerable importance in pressurized systems: the priority of such a strategy is not just the production of energy [14,15], but also the increase of sustainability and efficiency of water exploitation [2]. Filion et al. [16] showed that in the management of water distribution networks, a large energy recovery can be realized by exploiting the head drop due to the network pressure control strategy, that is, for leakage reduction. Thus, it is possible to install micro-hydropower plants by replacing traditional pressure regulation valves with energy production devices (EPD), such as turbines or pumps as turbines (PATs) [17-20]. Microturbines, such as the cross-flow ones, have also been proposed [21-23].

Energy recovery is an efficient solution to reduce pressure and increase the energy efficiency of water systems [24-29]. Nevertheless, the feasibility of energy recovery and the other abovementioned strategies depends on the amount of energy that can be saved, quantified by means of efficiency measures [30,31], and the costs of purchase, installation, management, and maintenance. Therefore, the calculation of the energy embedded in water streams $[3,10]$ is significant for the assessment of the efficiency of pressurized systems [32] and the evaluation of the potential of energy savings [33]. Gómez et al. and Cabrera et al. $[34,35]$ introduced some energy performance indicators that could provide a global view of energy efficiency; in particular, they introduced some indicative energetic amounts, with reference to two scenarios of a water distribution network. The first scenario was characterized by an indirect pumping towards an upstream reservoir that guaranteed a constant upstream head, whereas the second scenario presented a direct pumped supply to the network. The authors demonstrated that direct pumping is, by far, more convenient from both energetic and economic points of view. Nevertheless, the authors did not consider any energy recovery in the indirect pumping scheme, where a hydropower production plant, which converts the dissipation of the valves into energy, could increase the energy efficiency of the whole water system. Moreover, the indirect pumping towards an upstream reservoir can be considered a more resilient option, since in the case of power failure, the reservoir could provide a contingency supply for the emergency. Nevertheless, an upstream reservoir, located in the upper part of the network or an elevated tank, could have a serious environmental impact depending on its location and its size.

In this paper, a real network was assessed as a case study. The network was supplied by an upstream reservoir, and a part of the water energy should be dissipated within a valve, to reduce the pressure level and control leakage. Two different solutions to increase the energy efficiency of the network have been investigated. In the first solution, a PAT was used to replace the valve and recover energy. In the second case, the water was pumped directly from the source to the network, as suggested by $[34,35]$, bypassing the reservoir, with a smaller pumping head. The two scenarios have been compared in terms of required energy. Furthermore, the boundary condition of the network, that is, the source location and elevation, have been modified to compare the feasibility and the benefit of each of the two scenarios under differing design conditions. The efficiency of the two different technical solutions under variable values of pumping head, head losses, and head ratios between indirect and direct pumping have been investigated with the aid of a new energy index and two literature efficiency indices [34,35]. 


\section{Methodology}

\subsection{Study Area}

The case study concerns a rural water supply network in Ireland, located in County Laois, about $100 \mathrm{~km}$ from the capital city (Dublin). A reservoir is located at $147 \mathrm{~m}$ a.s.l. and supplied by a source placed at $99 \mathrm{~m}$ a.s.l. The studied branch of network consists of 55 nodes and 58 links. For each link, information about roughness, diameter, and length was available. Each node was characterized by an elevation and a demand coefficient, namely the ratio between the demand of the node and the demand of the whole network. The layout of the network is showed in Figure 1.

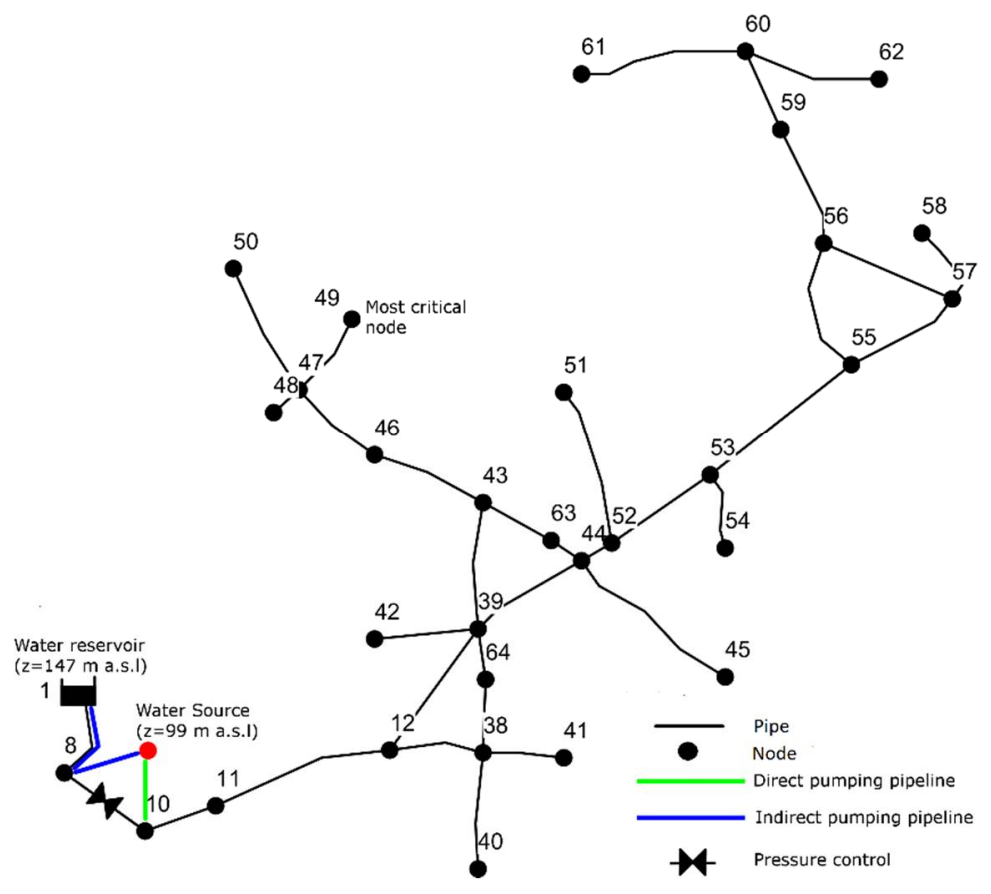

Figure 1. Hydraulic network of the study area.

A range of measured data was available, consisting of hourly values of flow rate for the year 2016, recorded at the link 8-10 (Figure 1). Node 8 was a zero-demand node, thus the measured discharge corresponded to the total demand of the network, if the leakage is neglected. The time series of the year-averaged hourly values of discharge $(Q(t))$ were calculated, resulting in the pattern in Figure 2, where time is expressed in hours. The average daily value of discharge, namely $\bar{Q}$, resulted as $4.35 \mathrm{~L} / \mathrm{s}$. The flow pattern of Figure 2 shows that the minimum value of discharge occurs at night-time and is higher than $3 \mathrm{~L} / \mathrm{s}$, about the $70 \%$ of the average discharge. This means that the amount of water leakage is very high and that a pressure control strategy is mandatory to increase the sustainability and the efficiency of the whole system. Probably a renovation of the pipeline could be also considered to further decrease the amount of leakage, but this choice will not be deeper investigated in this paper. 


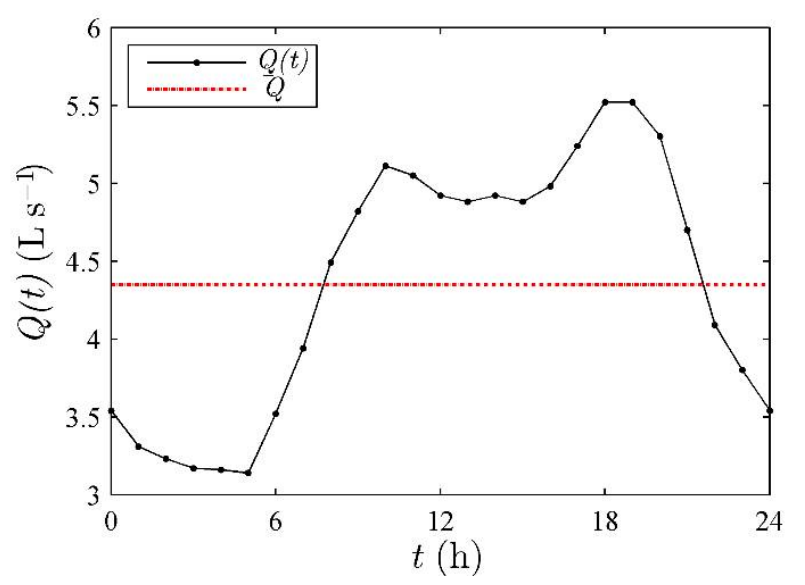

Figure 2. Average hourly values of discharge of the year 2016 referring to the link 8-10.

\subsection{Direct and Indirect Pumping}

The indirect pumping scenario consisted of a hydraulic configuration characterized by a pump supplying a reservoir. The supplied population is located in the downstream area and supplied by a network branching from the reservoir (Figure 3). Once the network arrives at a downstream village, a surplus of head is available due to changes in elevation. In the indirect pumping scenario, the surplus head can be either dissipated within a valve or exploited to produce energy by the employment of an EPD located downstream of the reservoir (Figure 3). In particular, a PAT was chosen for the reasons outlined in Section 2.3. In Figure $3 \Delta H_{\text {ind }}$ represents the pumping head in indirect supply scenario and $\triangle H_{P A T}$ is the head loss within the PAT.

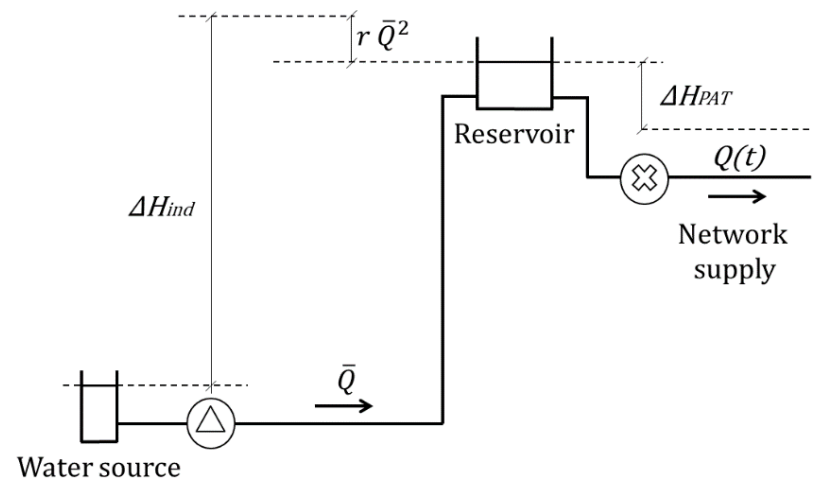

(2) PAT $\triangle$ Pump

Figure 3. Scheme of indirect pumping with energy recovery. PAT: pump as turbine.

The second scenario (Figure 4) presents a different hydraulic scheme: the upper reservoir was bypassed and pumping was performed directly from the source to the distribution network. The pump was designed to obtain the best possible efficiency and continuously regulated according to the request of the network, as described below in Sections 3 and 4.1. In Figure $4 \Delta H_{d i r}$ represents the pumping head of direct supply scenario. 


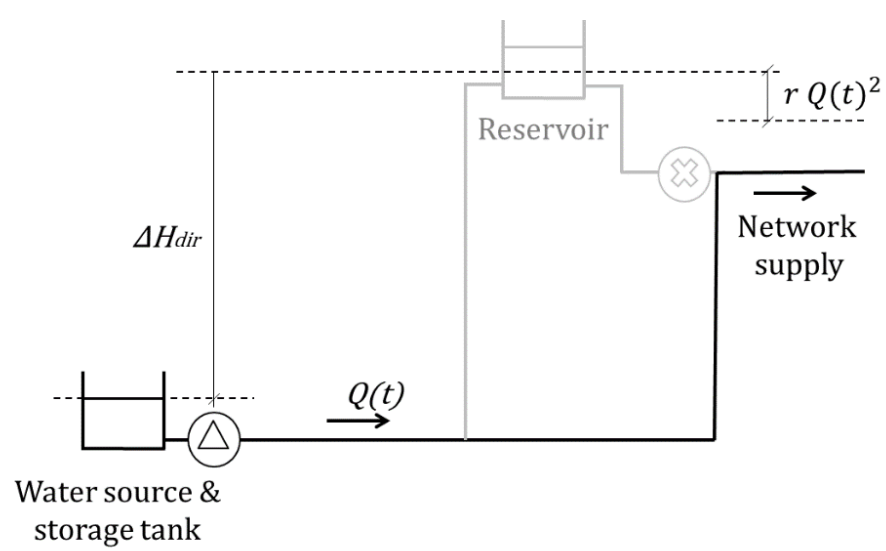

(3) PAT $\triangle$ Pump

Figure 4. Scheme of direct pumping.

The energy efficiency of the two cases has been analyzed, and an energy audit of the two scenarios is presented hereafter.

After the study of the real case, in order to get general results, the boundary conditions of the network, that is, the location and elevation of the source, have been arbitrarily changed to analyze different conditions and compare the feasibility and the benefit of each of the two scenarios in different cases.

\subsection{PAT and Microturbine Design/Operation}

Carravetta et al. [36] developed a method, the variable operating strategy (VOS), that allows the geometric selection of an EPD for a given flow-head distribution pattern and network backpressure, ensuring quite high efficiency values. The cost of a traditional turbine often exceeds its economic benefit, while a PAT or a microturbine have usually a limited cost [37]; moreover, PAT is generally preferred over a microturbine since it reduces further the plant cost: indeed, the miniaturized turbine has an average installation cost approximately equal to $1800 € / \mathrm{kW}$ [38], while the installation cost of a PAT could reach $350 € / \mathrm{kW}$ and its payback period is less than 1 year [39]. Nevertheless, PAT efficiency reaches the best efficiency point (BEP) around 0.6-0.7, so it is a bit lower than the maximum efficiency achieved by traditional turbines [37]. Although PATs are generally preferred over other devices, an obstacle to using them is represented by the lack of data, since manufacturers do not usually provide the performance curves of such devices. This scarceness of data can be overcome by using the affinity laws, once both the performance curves of a prototype PAT are known. Therefore, the affinity laws, which relate the performance of the prototype to the performance of a similar machine (having different diameter and rotational speed), allows the prediction of performance curves of other similar devices. Unfortunately, the affinity laws are based on the principle that the efficiency of similar devices is constant, although rotational speed varies. This result disagrees with the real behavior of turbomachines [40]; indeed, the efficiency of a machine is significantly dependent on the rotational speed, and the maximum efficiency is attained only at a given optimal speed value. Thus, the hypothesis of affinity laws is valid only in an established range of rotational speed, and the error in the prediction increases as the rotational speed of the prototype and the simulated device diverges. In spite of this, Fecarotta et al. [41,42] developed a model (relaxation of affinity equations: RAE) that predicts the variation of the efficiency with the runner speed. However, this model presents some limits since it can be considered valid only for an established category of machines with a specific range of speeds. Furthermore, a great problem in water distribution networks is represented by the need of ensuring a required head drop, under variable operating conditions; that is, head and discharge 
variations. To resolve this, it is necessary to include modulation plants [43], such as a hydraulic regulation (HR mode) or an electrical regulation (ER mode) [39,42].

\subsection{Pressure Management and Energy Recovery}

The network is provided with an upstream valve located along the pipe connecting nodes 8 and 10 (Figure 1) to control the pressure within the network. Instead of achieving a pressure control strategy by a usual regulation valve, exploitation of the head-drop to produce energy by an EPD has been opted for. In particular, a hydraulic regulation $[36,39]$ of the PAT was performed as described in Section 2.3. It consists of a regulation of hydraulic features in the network, by using a series-parallel hydraulic circuit (Figure 5).

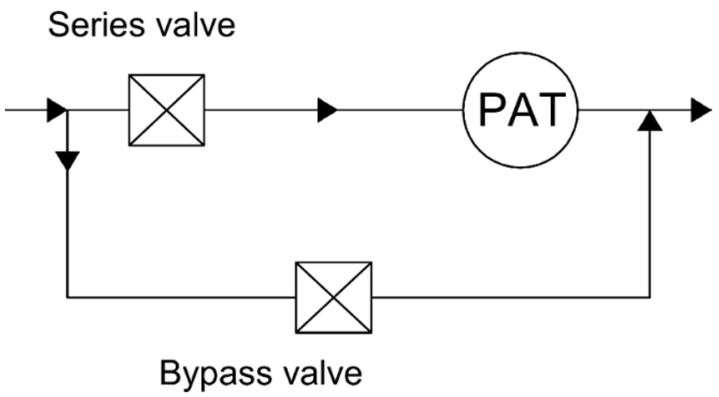

Figure 5. Scheme of the series-parallel hydraulic circuit [36,39].

As shown in Figure 5, the hydraulic circuit consists of two parallel branches with a PAT and two valves. When the head is higher than the head-drop deliverable by the machine, the excess of pressure is dissipated by a series pressure reducing valve (PRV). Instead, when the discharge is larger, the PAT would produce a head-drop higher than the available head, and a bypass is opened to reduce the discharge flowing in the PAT. Such hydraulic regulation (HR mode) was preferred over electrical regulation (ER mode), which consists of an inverter that modifies the frequency of the device, thus the rotational speed. Indeed, even if some power is dissipated by the series valve or bypassed by the parallel valve, the available power is still high and the HR mode presents a better efficiency than the ER mode, as well as a lower cost of equipment and a shorter payback period [36,39].

\section{Experimental Investigation}

\section{Pump under Variable Speed}

In water distribution networks, the water demand is time-dependent; thus, pumping in a direct scheme can be performed by a machine capable of such a variability, that is, working under variable speed. In this study, a centrifugal multistage end-suction pump HMU50-2/2 (Caprari S.p.A., Modena, Italy) was chosen as the reference machine and tested in the Hydro Energy Laboratory (HELab) of the University of Naples "Federico II". HELab was specifically realized to perform the test included in the new standard EN16480/2016, according to the specification of ISO 9906. The pump has been coupled to an asynchronous motor. Two pressure transducers ( $0-10$ bar and $-1-1.6$ bar, respectively; $\pm 0.1 \%$ accuracy) were used to measure the head, $\Delta H$, for each discharge value, $Q$, measured by a magnetic flow meter ( $0-15 \mathrm{~L} / \mathrm{s}, \pm 0.1 \%$ accuracy). A wattmeter ( $0-60 \mathrm{~kW}, \pm 0.3 \%$ accuracy) measured the input power, $P$, and an optical speedometer (0-380 rad / \pm 0.1 accuracy) was used to measure the rotational speed, $N$, of the pump. The motor was powered by a variable frequency driver to convert the $50 \mathrm{~Hz}$ input frequency to the desired value, $f$, to set the rotational speed of the pump. Figure 6 shows the dimensionless head, power, and efficiency curve of the pump, $h=h(q), p=p(q)$, and $\eta=\eta(q)$, respectively, as being:

$$
q=\frac{Q}{N D^{3}}, h=\frac{g \Delta H}{N^{2} D^{2}}, p=\frac{P}{\rho N^{3} D^{5}}
$$


where $g$ is the gravity acceleration, equal to $9.806 \mathrm{~m} / \mathrm{s}^{2} ; \rho$ the density of the water, about $1000 \mathrm{~kg} / \mathrm{m}^{3}$; and $D$ the diameter of the pump. The efficiency of the whole pumping system, $\eta$, for each operating condition, can be calculated as:

$$
\eta=\frac{q h}{p}
$$

The dimensionless head curve, $h=h(q)$, can be effectively approximated by a best-fit polynomial curve. Differently, a larger dispersion occurs for the power experimental points. In fact, the efficiency curve, $\eta=\eta(q)$, is different for each frequency $(f)$ value, depending on the behaviors of the pump, of the motor, and of the frequency drivers, as shown in Figure 6.

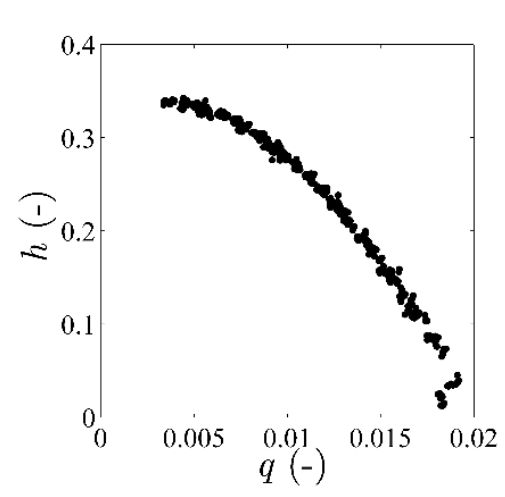

(a)

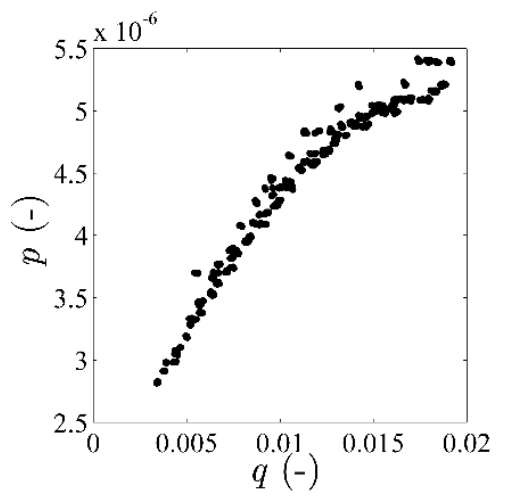

(b)

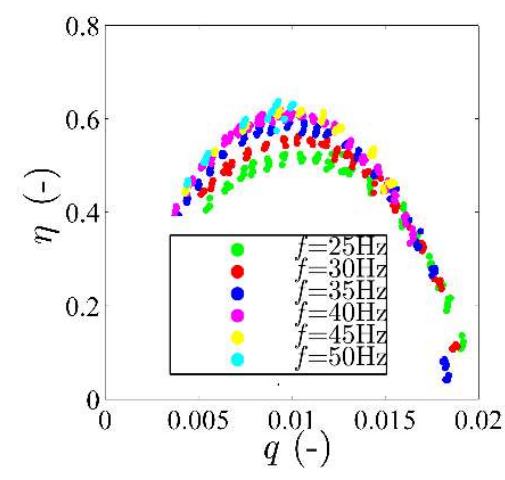

(c)

Figure 6. Dimensionless discharge $(q)$ against dimensionless head $(h)(\mathbf{a})$, power $(p)(\mathbf{b})$ and efficiency ( $)$ (c)of pump HMU50-2/2.

For each value of frequency, $f$, the value of efficiency at the BEP, $\eta_{B E P}$, was found. A trend of $\eta_{B E P}$ as a function of frequency has been identified, as shown in Figure 7. A best-fit polynomial approximation of second degree has been used to model the curve $\eta_{B E P}(f)$. It is shown in Figure 7 and expressed by a parametric form in Equation (3).

$$
\eta_{B E P}=a f^{2}+b f+c
$$

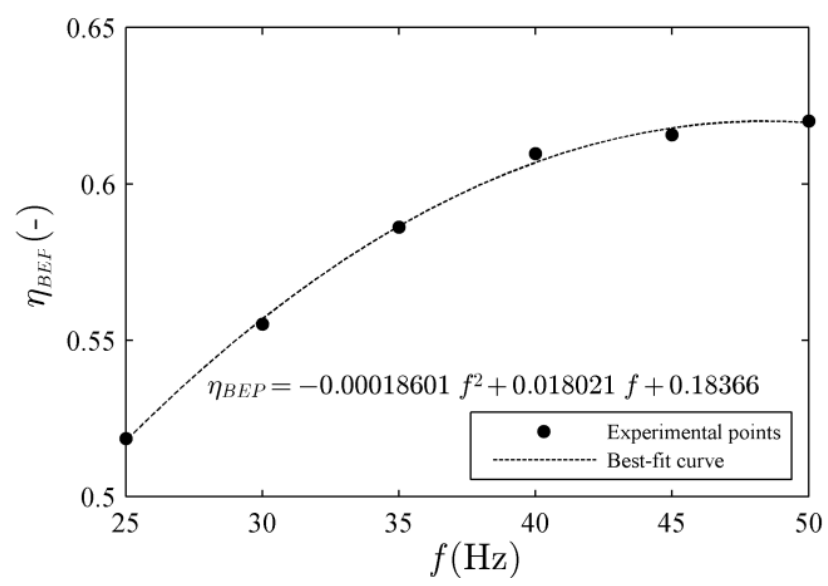

Figure 7. Best-fit polynomial curve of frequency against best efficiency point ( $f$ vs $\left.\eta_{B E P}\right)$. 
If the ratio between $\eta(q, f)$ and $\eta_{B E P}(f)$, namely $e$, is plotted against the dimensionless discharge, a trend of $e$ independent of the frequency is obtained, as shown in Figure 8.

$$
e=\frac{\eta(q, f)}{\eta_{B E P}(f)}=e(q)
$$

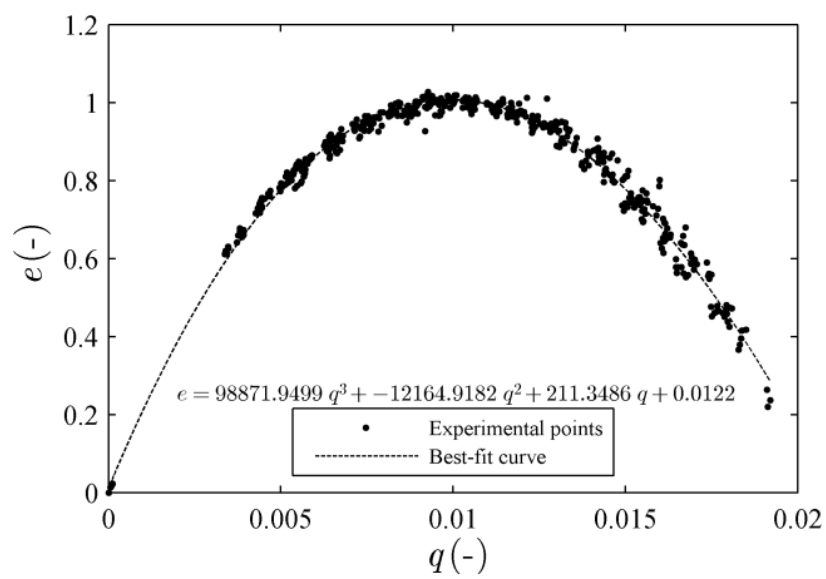

Figure 8. Experimental measurements of $e$ against the dimensionless discharge $e(q)$ and best-fit line.

Furthermore, for an asynchronous motor, the rotating speed, $N$, can be considered a function of the grid frequency, $f$, according to Equation (5), wherein $p p$ is the number of pole pairs for each phase.

$$
N=\frac{2 \pi f}{p p}
$$

Thus, if the impeller diameter, $D$, and the frequency, $f$, are known, for each value of discharge $(Q)$, the head $(\Delta H)$ can be calculated by (1) and the polynomial best fit of the $h$ curve. Then, $e, \eta_{B E P}$, and $\eta$ can be calculated by (2)-(4). Therefore, the absorbed power can be calculated as hydraulic power, $P_{h y d r}$, as shown in Equation (6).

$$
P=\frac{P_{h y d r}}{\eta(q, f)}
$$

$P_{h y d r}$ being:

$$
P_{h y d r}=\gamma \Delta H Q
$$

and $\gamma$ the specific weight of water, $9806 \mathrm{~N} / \mathrm{m}^{3}$. For the tested pump, with a $D=170 \mathrm{~mm}$ impeller, at the maximum frequency $f=50 \mathrm{~Hz}$, the discharge, head, and efficiency at the BEP resulted in: $Q_{B E P}=14 \mathrm{~L} / \mathrm{s}, \Delta H_{B E P}=81.9 \mathrm{~m}$, and $\eta_{B E P}=0.63$. If the methodology described in EN16480/2016 is applied, then a minimum efficiency index (MEI) equal to 0.6 can be assigned to the pump.

The same machine has been tested in turbine mode, with reversed flow, in the laboratory of Caprari SPA, Modena (I). Only the hydraulic part has been tested, without the generator, and the mechanical power was measured at the PAT shaft by a torque meter $(0-1000 \mathrm{Nm}, 0-380 \mathrm{rad} / \mathrm{s}, \pm 0.2 \%$ accuracy). Similar flow meter and pressure transducers were used for the discharge and pressure measurements. The results are plotted in Figure 9 in terms of dimensionless parameters. 


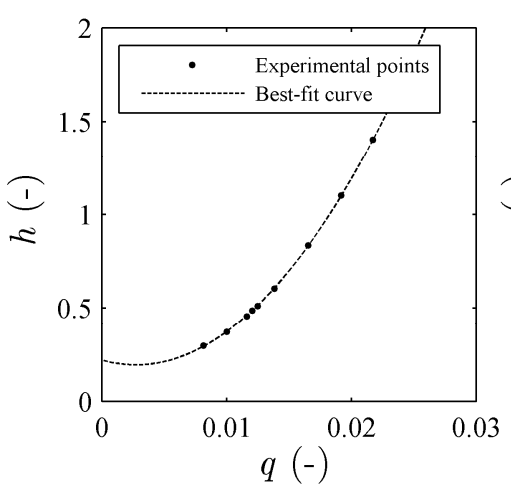

(a)

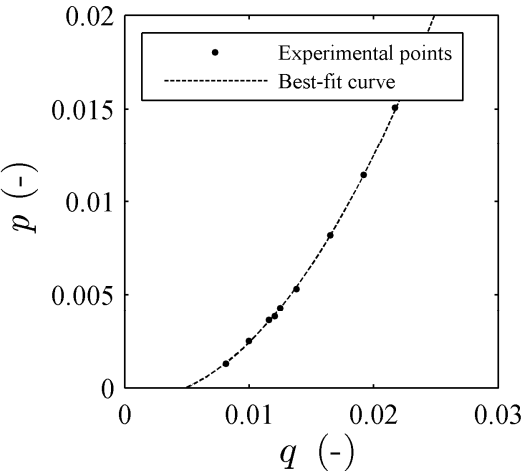

(b)

Figure 9. Dimensionless discharge $(q)$ against dimensionless head $(h)(\mathbf{a})$ and power $(p)(\mathbf{b})$ of PAT HMU50-2/2.

\section{Application to the Case Study Network}

\subsection{Indirect Pumping}

In this scenario, the average demand is pumped from the source to the reservoir. The pumping head, namely $\Delta H_{\text {ind }}$, is the sum of the head loss within the pipe and the difference of elevation between the reservoir and the source. The discharge at the BEP, namely $Q_{B E P}$, is set equal to the annual daily average discharge, $\bar{Q}$. The pipe linking the source and the reservoir is $1069 \mathrm{~m}$ long with a $200 \mathrm{~mm}$ diameter. The roughness of the pipe was set as $0.26 \mathrm{~mm}$, comparable to the values of the whole network. A Darcy-Weisbach formula was used to calculate the head loss within the pipe, which is expected to be very low, since the combination of all previous parameters makes the approaching pipe oversized.

In order to obtain an approximate value of the energy consumption, the minimum efficiency of the standard pumps, suggested by EN 16480/2016 and presented in Equation (8), was referred to.

$$
\eta_{B E P}=-11.48\left(\ln \left(n_{S}\right)\right)^{2}-0.85\left(\ln \left(n_{S}\right)\right)^{2}-0.38 \ln \left(n_{S}\right) \ln \left(Q_{B E P}\right)+88.59 \ln \left(n_{S}\right)+13.46 \ln \left(Q_{B E P}\right)-C
$$

where $Q_{B E P}$ is the flow at the BEP condition measured in $\mathrm{m}^{3} / \mathrm{h} ; C$ is a constant depending both on the minimum efficiency index (MEI) and the model of pump; and $n_{S}\left(\mathrm{~min}^{-1}\right)$ is the specific speed whose expression is:

$$
n_{s}=N \frac{\sqrt{Q_{B E P}}}{H_{B E P^{0.75}}}
$$

wherein $N$ is the rotational speed of the pump and $H_{B E P}$ is the pressure head at the BEP condition, set equal to $\Delta H_{\text {ind }}$. If the MEI is fixed equal to 0.6 , as the one of the tested pump, and an end suction own bearing (ESOB) pump with a rotational speed of $2900 \mathrm{rpm}$ is chosen, then $C$ results as 128.12.

Therefore, the absorbed energy $E_{\text {ind }}$ can be expressed by Equation (10).

$$
E_{\text {ind }}=\frac{E_{\text {hydr,ind }}}{\eta_{B E P} \eta_{M O T}}=T \frac{\Upsilon \Delta H_{\text {ind }} \bar{Q}}{\eta_{B E P} \eta_{M O T}}
$$

where $T$ is the reference time period, that is, one year. In Equation (10), $\eta_{M O T}$ represents the efficiency of the motor belonging to the IE3 efficiency class, suggested by EC Regulation 640/2009. Furthermore, such a procedure was also implemented by varying the number of stages between one and fifteen, choosing the number of stages that allowed the maximum efficiency. For the case study, the optimal number of stages resulted as 7 and the required energy $E_{\text {ind }}$ was calculated as 32,420 kWh/year. 


\subsection{Pressure Management}

Referring to Figure 1, to reduce the pressure in the network, for each hour, the head downstream of the valve, $H_{\text {req }}$, and thus drop within the valve, was set to ensure a minimum value of $10 \mathrm{~m}$ in the most critical downstream node (node 49). The hydraulic simulator Epanet has been used to estimate available head versus flow variation during the day. Then, the valve was replaced with a PAT to recover the dissipated energy. The time series (in hours) of the flow $(Q(t))$ and the head loss within the PAT system in link 8-10 $\left(\Delta H_{P A T}\right)$ for the average day are presented in Figure 10, along with the $(\Delta H, Q(t))$ pattern.

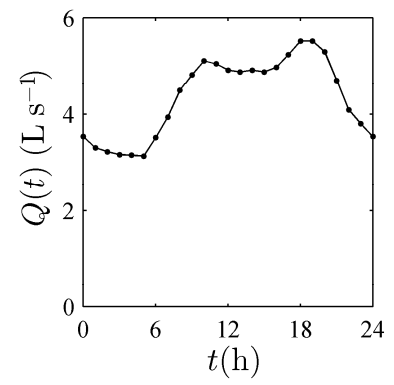

(a)

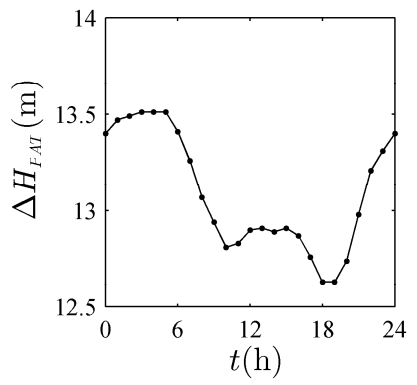

(b)

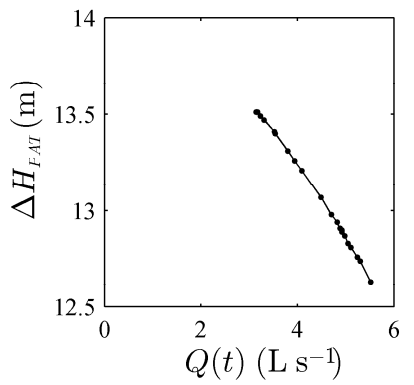

(c)

Figure 10. Time series of flow (a) and head loss (b) through the valve; pattern $\Delta H, Q(t)$ (c).

Thus, the variable operating strategy $[36,39]$ was implemented in order to find the optimal PAT, that is, the impeller diameter and its rotational speed, that maximizes the produced energy $E_{P A T}$ :

$$
E_{P A T}=\int_{T} \Upsilon \Delta H_{P A T} Q \eta d t
$$

The experimental curves of the PAT described above have been used as reference curves, and the affinity law was used to simulate similar machines having different diameter and rotational speed. The MATLAB (R2012b, MathWorks, Inc., Natick, MA, USA)optimization toolbox was used to perform this optimization [44,45]. In particular, the diameter was varied between $80 \mathrm{~mm}$ and $500 \mathrm{~mm}$, whereas the values of rotational speed considered were $1025 \mathrm{rpm}$ (three couples of poles), $1550 \mathrm{rpm}$ (two couples of poles), and $3100 \mathrm{rpm}$ (one couple of poles). The rotational speed and the diameter of the optimal machine resulted in $155 \mathrm{~mm}$ and $1025 \mathrm{rpm}$, respectively. Then, for each hour, the power delivered by the PAT was obtained and this energy was further multiplied by the efficiency of the generator (EI3 class), as suggested by EC Regulation 640/2009. Referring to the chosen PAT, the produced energy was accounted as $2234 \mathrm{kWh} /$ year.

\subsection{Direct Pumping}

In the direct pumping scenario, the upper reservoir is bypassed and the water is directly pumped from the source to the network (node 10 of Figure 1). The approaching pipe is $710 \mathrm{~m}$ length with a $200 \mathrm{~mm}$ diameter. The roughness of the pipe was set as $0.26 \mathrm{~mm}$, comparable to the values of the whole network. A Darcy-Weisbach formula was used to calculate the head loss within the pipe. The required head was set equal to the head downstream of the valve in the indirect pumping scenario $\left(H_{\text {req }}\right)$. Thus, a minimum $10 \mathrm{~m}$ pressure in the most critical node of the whole network was ensured. The pumping discharge in the direct scenario is variable according to Figure 2, as well as the pumping head $\left(\Delta H_{\text {dir }}\right)$, which depends on the required head and the head loss. Given the variable pattern of pumping discharge and head, the pump should be equipped with a variable frequency driver to modify the rotational speed according to the network requests. The design of the pump was performed by an optimization routine $[44,45]$ in order to find the values of the number of stages (varied between 
one and fifteen, as in the indirect pumping scenario), the diameter $(D)$, and the hourly rotational speed $(n)$, both minimizing daily energy usage and ensuring the required pressure head for each hour. The measured performance curves of the pump showed above were used as reference curves to apply the affinity law equations. Therefore, the energy absorbed by the pump to be optimized was calculated by Equation (12).

$$
E_{d i r}=\int_{T} \frac{\Upsilon \Delta H_{d i r} Q}{\eta} d t
$$

For the analyzed case study, the optimal diameter resulted as $116 \mathrm{~mm}$, the rotational speed varying from $2679 \mathrm{rpm}$ to $3000 \mathrm{rpm}$, and the number of stages as 2 . The total amount of energy was calculated as $22,327 \mathrm{kWh} /$ year.

\section{Results}

To analyze the results and to compare the different scenarios, the following two indices have been defined.

$$
\begin{gathered}
E I_{1}=\frac{E_{\text {ind }}-E_{P A T}-E_{\text {dir }}}{E_{\text {ind }}}=\frac{\Delta E}{E_{\text {ind }}} \\
E I_{2}=\frac{E_{\text {ind }}-E_{\text {dir }}}{E_{\text {ind }}}
\end{gathered}
$$

where $\left(E_{\text {ind }}-E_{P A T}\right)$ represents the energy consumption of the indirect pumping scenario with energy recovery; $E_{d i r}$ represents the energy spent in the direct pumping scenario; and $E_{\text {ind }}$ is the energy consumption of the indirect pumping scenario in the absence of energy recovery. Thus, $\Delta E$ represents the difference in energy spent in both the scenarios. The first index, $E I_{1}$, measures the convenience of the direct pumping scenario when compared to the scenario with indirect pumping and energy recovery. If the index is positive, the energy required to pump water directly to the network is lower than the energy required by the indirect scenario. This is the difference between the energy required by indirect pumping and the energy recovered by the PAT. The second index, $E I_{2}$, measures the convenience of one of the two scenarios when no energy is recovered by any EPD.

In both $E I_{1}$ and $E I_{2}$, the amount of energy that is saved due to the reduction of leakage is not considered, even if it can be a considerable value. Such a calculation can be very difficult, since a complete model of the network is needed to relate the pressure and the amount of leakage. However, the pressure distribution along the network is equal for both scenarios, thus the contribution of water saving is equal both for indirect and direct pumping.

Referring to the case study, $E I_{1}$ is equal to 0.24 and $E I_{2}$ is 0.31 . This means that for the case study network, up to $31 \%$ of energy can be saved if a strategy of direct pumping of water to the network is adopted. Furthermore, the amount of energy that can be saved by a PAT is lower than the saving performed by direct pumping. In fact, in the direct pumping scenario, the required daily energy is equal to $61 \mathrm{kWh} /$ day, while the indirect pumping daily energy is equal to $89 \mathrm{kWh} /$ day and $6 \mathrm{kWh} /$ day can be recovered by the PAT. Then, the energy losses due to the efficiency of the two machines (indirect pump and PAT) contribute to make the direct pumping scenario more convenient. In Table 1, the main

\begin{tabular}{|c|c|c|c|c|c|}
\hline Scenario & $\begin{array}{l}\text { Pumping Head } \\
\text { (m) }\end{array}$ & $\begin{array}{c}\text { Energy } \\
\text { (kWh/Year) }\end{array}$ & $\begin{array}{l}\text { Efficiency Index } \\
\qquad E I_{1}\end{array}$ & $\begin{array}{l}\text { Efficiency Index } \\
\qquad E I_{2}\end{array}$ & $\begin{array}{c}\text { Recovered Energy } \\
(\mathrm{kWh} / \text { Year })\end{array}$ \\
\hline Indirect & 48.14 & 32,420 & \multirow{2}{*}{0.24} & \multirow{2}{*}{0.31} & 2234 \\
\hline Direct & 34.88 & 22,327 & & & - \\
\hline
\end{tabular}
figures of the two scenarios are reported.

Table 1. Main figures of the indirect and direct pumping scenarios.

The analyzed conditions do not cover all the design solutions. Indeed, indirect pumping could be operated only during the night when the energy cost is cheaper. During the day, when the flow 
demand and the price of the energy are higher, water could be provided from the reservoir. In such a case, the volume of the storage tank should be large enough to ensure the reserve of water for the whole day. The most convenient solution depends on multiple factors, such as the real price of energy, civil works, and the feed-in tariff regulation (the selling price of renewables). A deeper analysis should include a life cycle assessment [5] in order to also consider the environmental sustainability.

\subsection{Energy Indices under Differing Boundary Conditions}

For the sake of generality, some differing boundary conditions have been studied, by varying the pumping head of both scenarios, corresponding to different distances and elevations of the source from the distribution. For the indirect pumping scenario, different values of pressure head were assigned, namely $\Delta H_{\text {ind }}=25 \mathrm{~m}, \Delta H_{\text {ind }}=50 \mathrm{~m}$, and $\Delta H_{\text {ind }}=100 \mathrm{~m}$. Then, for each value of $\Delta H_{\text {ind }}$, several values of the average pressure head $\left(\overline{\Delta H_{\text {dir }}}\right)$ have been considered, setting the ratio $i_{1}$ between 0.5 and 1.5 , $i_{1}$ being:

$$
i_{1}=\frac{\overline{\Delta H_{\text {dir }}}}{\Delta H_{\text {ind }}}
$$

Indeed, even if the required head at the end of the pipeline in direct pumping is lower, $\overline{\Delta H_{d i r}}$ can be larger than $\Delta H_{\text {ind }}$ due to the head losses, that is, due to a smaller diameter pipe or a longer path. Then, for each value of $\Delta H_{\text {ind }}$ and $i_{1}$, several values of head loss in the approaching pipe in the direct pumping scenario have been considered, setting $i_{2}$ to $25 \%, 50 \%$, and $75 \%$, where $i_{2}$ is the ratio between the head loss produced by the average daily discharge, $\bar{Q}$, calculated by the Hazen-Williams formula, and $\Delta H_{\text {ind }}$ :

$$
i_{2}=\frac{J L}{\Delta H_{\text {ind }}}=\frac{\frac{10.67 \overline{\mathrm{Q}}^{1.852} L}{K^{1.852} D^{4.8704}}}{\Delta H_{\text {ind }}}=\frac{r \bar{Q}^{1.852}}{\Delta H_{\text {ind }}}
$$

where $L$ and $D$ represent the length and the diameter of the pipe linking the water source and the network, respectively; $K$ is the roughness coefficient corresponding to a different material of the aforementioned pipe; and $\bar{Q}$ is the average daily demand of the network, equal to $4.35 \mathrm{~L} / \mathrm{s}$. The terms $L, D$, and $K$ were assembled in only one term, namely $r$.

For each combination of $\Delta H_{\text {ind }}, i_{1}$, and $i_{2}$, the amount of required energy in both scenarios has been evaluated and the two indices, $E I_{1}$ and $E I_{2}$, have been calculated.

Figure 11 shows the values of $E I_{1}$ and $E I_{2}$ when $\Delta H_{\text {ind }}$ is set to $25 \mathrm{~m}$.

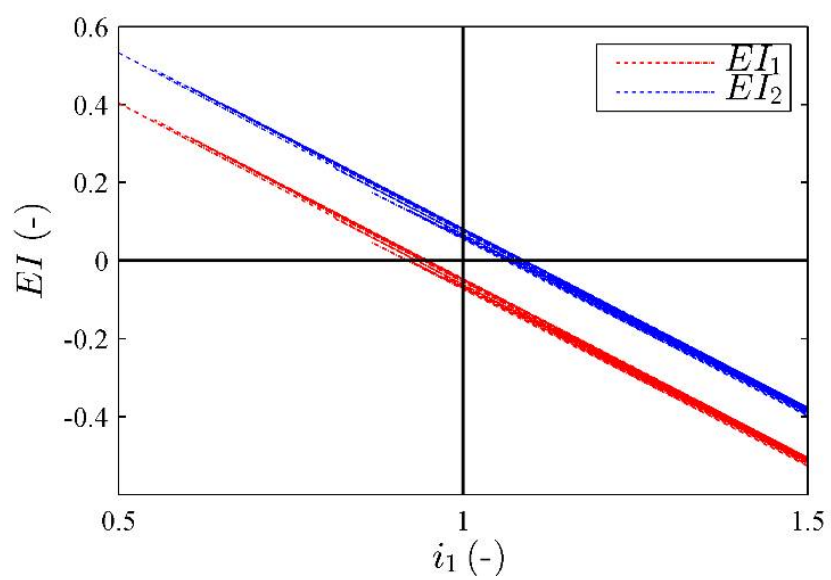

Figure 11. Trend of efficiency indices for $\Delta H_{\text {ind }}=25 \mathrm{~m}$ with $i_{2}$ equal to $25 \%, 50 \%$, and $75 \%$, respectively.

For each value of $i_{1}$, a very small variability of both indices occurs depending on $i_{2}$. This means that the head loss has a very small influence on the energy efficiency of the system. Furthermore, where $i_{1}$ is equal to 1 , that is, when $\overline{\Delta H_{d i r}}$ is equal to $\Delta H_{\text {ind }}$, indirect pumping with energy recovery 
is more convenient ( $E I_{1}$ is negative) and this saving amounts to about $5 \%$. Instead, in the condition of no energy recovery, the most convenient scenario is direct pumping and the benefit amounts to around $8 \%$. Furthermore, in the absence of energy recovery, direct pumping is the most convenient scenario until a value of $\overline{\Delta H_{d i r}}=1.09 \cdot \Delta H_{\text {ind }}$; instead, the convenience of such a scenario decreases in the condition of energy recovery: indeed, direct pumping is the favorite scenario until a value of pressure head of approximately $\overline{\Delta H_{d i r}}=0.94 \cdot \Delta H_{\text {ind }}$ is reached. Obviously, both indices increase as $i_{1}$ decreases; that is, the convenience of direct pumping increases as the direct pumping head decreases.

Figure 12 shows that by increasing $\Delta H_{\text {ind }}$ to $50 \mathrm{~m}$ and $100 \mathrm{~m}$, for $i_{1}$ equal to 1 , the convenience of indirect pumping with energy recovery reduces to $2 \%$ for $\Delta H_{\text {ind }}=50 \mathrm{~m}$ and $0.5 \%$ for $\Delta H_{\text {ind }}=100 \mathrm{~m}$. This reduction happens because the amount of energy that can be recovered by the PAT decreases with respect to the total energy required for the pumping. In the absence of energy recovery, direct pumping is still the most convenient scenario, although such a convenience decreases to around $5 \%$ for $\Delta H_{\text {ind }}=50 \mathrm{~m}$ and $3 \%$ for $\Delta H_{\text {ind }}=100 \mathrm{~m}$. If no energy recovery is applied, then the direct pumping scenario can be considered convenient up to $i_{1}=1.04\left(\Delta H_{\text {ind }}=50 \mathrm{~m}\right)$ and $1.02\left(\Delta H_{\text {ind }}=100 \mathrm{~m}\right)$. When energy recovery is performed by a PAT, the indirect pumping is convenient for $i_{1}$ greater than 0.98 when $\Delta H_{\text {ind }}=50 \mathrm{~m}$ and greater than 0.99 when $\Delta H_{\text {ind }}=100 \mathrm{~m}$. Such a behavior probably occurs because $E_{P A T}$ is constant among the different conditions and its relevance decreases as $\Delta H_{\text {ind }}$ (and thus $\overline{\Delta H_{d i r}}, E_{i n d}$, and $E_{d i r}$ ) increases. The convenience of direct pumping increases as $i_{1}$ decreases. The previous results are shown in Table 2, where "saving" represents the percentage of energy saved by indirect pumping (in the condition of energy recovery) and by direct pumping (in the absence of energy recovery) for $i_{1}$ equal to 1 . Moreover, in Table 2, "direct scenario cutoff" represents the value of $\overline{\Delta H_{\text {dir }}}$ until which direct pumping is the most convenient scenario.

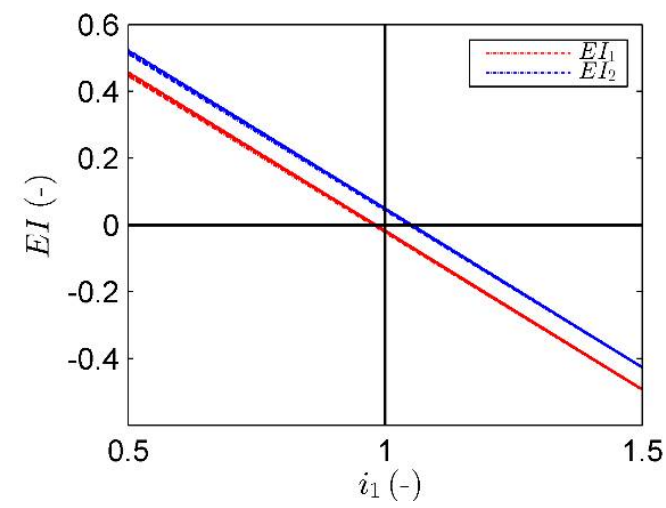

(a)

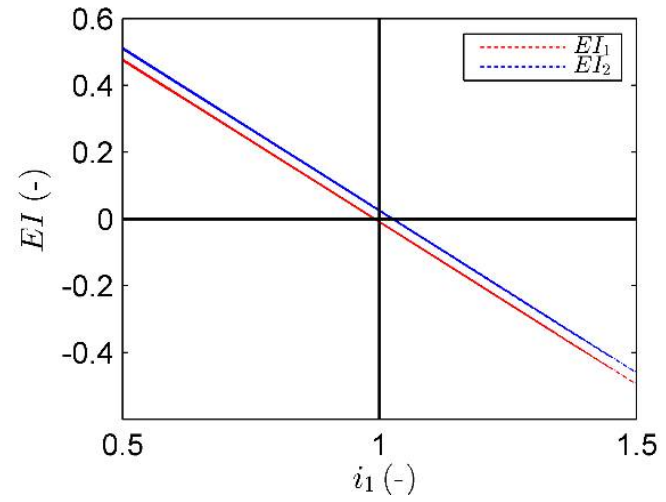

(b)

Figure 12. Trend of efficiency indices for $\Delta H_{\text {ind }}=50 \mathrm{~m}(\mathbf{a})$ and $\Delta H_{\text {ind }}=100 \mathrm{~m}(\mathbf{b})$, with $i_{2}$ equal to $25 \%$, $50 \%$, and $75 \%$, respectively.

Table 2. Main figures of the indirect and direct pumping scenarios.

\begin{tabular}{ccccc}
\hline \multirow{2}{*}{$\Delta \boldsymbol{H}_{\text {ind }}(\mathbf{m})$} & \multicolumn{2}{c}{ Energy Recovery } & \multicolumn{2}{c}{ No Energy Recovery } \\
\cline { 2 - 5 } & Saving (\%) & Direct Scenario Cutoff & Saving (\%) & Direct Scenario Cutoff \\
\hline 25 & 5 & $0.94 \Delta H_{\text {ind }}$ & 8 & $1.09 \Delta H_{\text {ind }}$ \\
50 & 2 & $0.98 \Delta H_{\text {ind }}$ & 5 & $1.04 \Delta H_{\text {ind }}$ \\
100 & 0.5 & $0.99 \Delta H_{\text {ind }}$ & 3 & $1.02 \Delta H_{\text {ind }}$ \\
\hline
\end{tabular}




\subsection{Previously Reported Energy Indices for Different Boundary Conditions}

Gómez et al. and Cabrera et al. [34,35] introduced some efficiency indices of ideal $\left(\eta_{a i}\right)$ and real $\left(\eta_{a r}\right)$ systems. These indices are presented in Equations (17) and (18).

$$
\begin{gathered}
\eta_{a i}=\frac{E_{u o}}{E_{s i}}=\frac{E_{u o}}{E_{u o}+E_{t i}+E_{e i}} \\
\eta_{a r}=\frac{E_{u o}}{E_{s r}}=\frac{E_{u o}}{E_{u o}+E_{t r}+E_{e r}+E_{r g}}=\frac{E_{u o}}{E_{s r, n}+E_{s r, p}}
\end{gathered}
$$

In these equations, $E_{u o}$ is the minimum required energy by users (no matter whether the system is ideal or real), $E_{t i}$ is the topographic energy required by an ideal system, and $E_{e i}$ is the supplied excess energy for an ideal system. Moreover, real system efficiency is characterized by an additional term, $E_{r g}$, representing reducible global energy. Furthermore, $E_{s r, n}$ and $E_{s r, p}$ are the natural and shaft energy supplied to the system, respectively. $E_{u o}$ is related to the topography of the network and is constant. $E_{s r, n}$ depends on the location and the elevation of the source, and $E_{s r, p}$ is the energy spent by pumping. The energy recovered by the PAT is subtracted to $E_{s r, p}$ for the calculation of $\eta_{a r}$.

The authors of $[34,35]$ defined these indices to give an overview of the energy efficiency of the supply system and the whole distribution. Applying these to the current case study, for the indirect pumping scenario, $\eta_{a i}$ is equal to 0.37 , whereas $\eta_{a r}$ is equal to 0.24 with energy recovery $\left(\eta_{a r, 1.2}\right)$ and 0.22 otherwise $\left(\eta_{a r, 1.2}\right)$. In the direct pumping scenario, $\eta_{a i}$ and $\eta_{a r}$ (i.e., $\left.\eta_{a r, 2}\right)$ can be evaluated as 0.46 and 0.30 . The higher efficiency of the direct pumping scenario highlights its convenience for this case study. In Table 3, the main figures of the two scenarios are reported.

Table 3. Main figures of the indirect and direct pumping scenarios: efficiency index of ideal system $\left(\eta_{a i}\right)$, efficiency index of real indirect pumping system with energy recovery $\left(\eta_{a r, 1.2}\right)$ and otherwise $\left(\eta_{\text {ar, 1.2 }}\right)$, efficiency index of real direct pumping system $\left(\eta_{a r, 2}\right)$.

\begin{tabular}{ccccc}
\hline Scenario & $\eta_{a i}$ & $\eta_{a r, \mathbf{1 . 1}}$ & $\eta_{a r, \mathbf{1 . 2}}$ & $\eta_{a r, \mathbf{2}}$ \\
\hline Indirect & 0.37 & 0.24 & 0.22 & - \\
\hline Direct & 0.46 & - & - & 0.30 \\
\hline
\end{tabular}

The two efficiency indices showed above have been calculated for different conditions of sourcing, that is, different values of $i_{1}$ and $i_{2}$. Figure 13 shows trends of the $\eta_{a r}$ efficiency index with $i_{1}$ for different values of $\Delta H_{\text {ind }}$ and $i_{2}$.

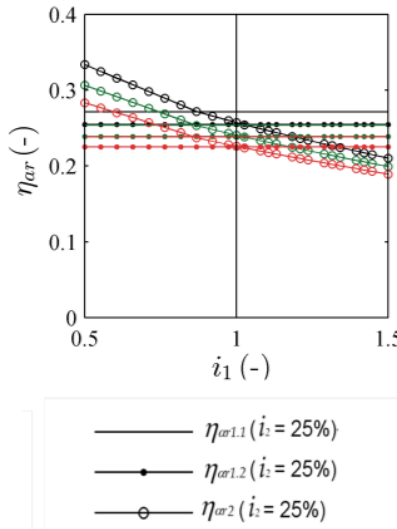

(a)

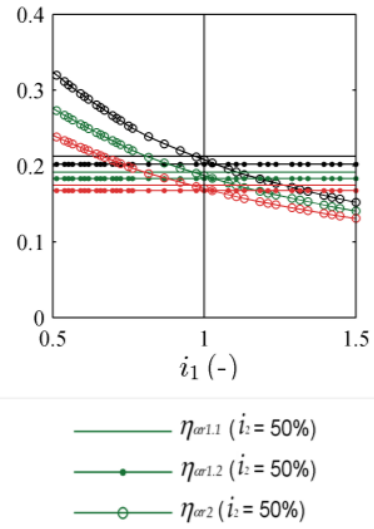

(b)

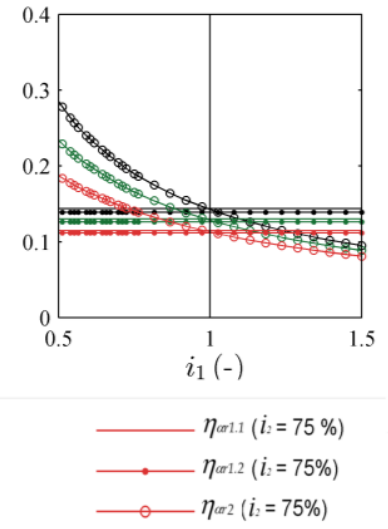

(c)

Figure 13. Trend of efficiency indices reported by the authors of [34,35] for $\Delta H_{\text {ind }}=25 \mathrm{~m}$ (a); $\Delta H_{\text {ind }}=50 \mathrm{~m}(\mathbf{b})$; and $\Delta H_{\text {ind }}=100 \mathrm{~m}$ (c). 
As shown in Figure 13, for an assigned value of $i_{1}$, the efficiency reduces with increasing $i_{2}$. Indeed, a higher value of $i_{2}$ means a higher proportion of head loss on the total pumping head. This leads to higher elevation of the source, thus higher values of natural energy $E_{s r, n}$. From Equation (18), if $E_{s r, n}$ increases, then $\eta_{a r}$ decreases.

Furthermore, the comparison between the values of $\eta_{a r, 1.1}$ and $\eta_{a r, 2}$ gives information about the convenience of each of the two scenarios. As demonstrated above, the convenience of direct pumping increases for decreasing $i_{1}$. Thus, direct pumping can be considered more convenient if a certain amount of the pumping head can be saved by bypassing the storage reservoir upstream of the network. The plot of Figure 13, similarly to Figures 11 and 12, shows that even in the presence of energy recovery, if the reduction of pumping head is significant, that is, $i_{1}$ is lower than a certain value, then direct pumping is the more convenient strategy. Nevertheless, for $H_{\text {ind }}=25 \mathrm{~m}$, the $\eta_{\text {ar }}$ efficiency of direct pumping is higher for values of $i_{1}$ lower than 0.88 , whereas the calculation of $E I_{1}$ shows that the cutoff occurs for $i_{1}$ equal to 0.94 . Similarly, for $H_{\text {ind }}=50 \mathrm{~m}$ and $H_{\text {ind }}=100$, the analysis of the values of $\eta_{\text {ar }}$ could lead to slightly different results in terms of this energy audit, if compared with the values of Figures 11 and 12 .

Finally, even if the calculation of $\eta_{a r}$ gives an overview of the mutual convenience of the two practices, it does not give detailed information about the amount of energy that can be saved in either of the two scenarios.

\section{Conclusions}

In this paper, the energy efficiency of the supply system of a water distribution network is discussed. A branch of a real water distribution network has been adopted as a case study, serving the area of Ballacolla (IE) with an average daily discharge of $4.35 \mathrm{~L} / \mathrm{s}$. The amount of water leakage within the network is very high, since during the night-time, the minimum discharge is about $70 \%$ of the average daily discharge. A pressure control strategy is mandatory for this network to save water and the energy embedded. A renovation of the pipeline could be also considered to further decrease the amount of leakage, but this choice has been not investigated in this paper.

The case study is representative of many situations that occur in water systems, where the water is pumped to an elevated tank or reservoir and then distributed to the network after a pressure reduction to control the water leakage. The energy requirement was assessed as $32,420 \mathrm{kWh} /$ year to pump the water from the source to the reservoir, while an average value of $5075 \mathrm{kWh} /$ year of hydraulic energy has been assessed as being dissipated within the valve.

Two alternative scenarios have been considered to increase the energy efficiency of the system: (i) reducing the pressure downstream of the reservoir replacing the valve with a PAT to recover energy and control the pressure; or (ii) bypassing the upstream reservoir and directly supplying the network from the source at the required pressure value with a variable speed pump. An energy audit of both scenarios has been presented.

In the first case, the PAT allowed the saving of $2234 \mathrm{kWh} /$ year, while the variable speed pump in the direct pumping scenario required $22,327 \mathrm{kWh} /$ year, with a saving of $10,090 \mathrm{kWh}$ /year. Thus, as already predicted by some studies, the case study seems to demonstrate that direct pumping can be considered as more efficient than indirect pumping, even if the system is provided with an energy recovery device such as a PAT or a turbine.

For the sake of generality, some other supply conditions have been simulated, corresponding to different combinations of source location, source elevation, head loss in direct pumping, and head loss in indirect pumping. An energy index has been defined to compare and analyze the results. The study gave more comprehensive information about the benefit of either of the two scenarios. The direct scenario is more convenient when no PAT is provided for energy recovery, unless the direct pumping head is too high, that is, due to higher head losses in the approaching pipe. Nevertheless, when the system is equipped for the energy recovery, the results slightly change. When the values of pumping head both in the direct and indirect scenarios are equal, indirect pumping with energy recovery is 
up to $8 \%$ more convenient than direct pumping. In fact, direct pumping becomes advantageous as long as the pumping head can be reduced, and its convenience increases as such a reduction increases. A similar behavior can be observed by the analysis of the efficiency indices proposed by Gómez et al. [34] and Cabrera et al. [35].

In conclusion, the direct pumping scenario could be convenient if the pumping head could be reduced (up to $6 \%$ ) and the variable speed pump ensures the correct operation of the network, avoiding the high environmental impact of a reservoir. Nevertheless, in certain cases, indirect pumping to an elevated tank or reservoir can be an advantageous practice, if the system is provided with a PAT for energy recovery. In the latter case, the presence of a reservoir increases the resilience of the water system, for example, in the case of a power failure. The optimal solution must be studied case by case, depending on the hydraulic conditions of the system and on the real costs and benefits of each possible design solution.

Author Contributions: All the authors contributed equally to this work.

Acknowledgments: This paper was partly funded by the European Regional Development Fund (ERDF) Interreg Atlantic Area Programme 2014-2020, through the Reduction Energy Dependency in Atlantic area Water Networks (REDAWN) project EAPA 198/2016.

Conflicts of Interest: The authors declare no conflict of interest.

\section{References}

1. Abbott, M.; Cohen, B. Productivity and efficiency in the water industry. Util. Policy 2009, 17, 233-244. [CrossRef]

2. Pérez-Sánchez, M.; Sánchez-Romero, F.J.; Ramos, H.M.; López-Jiménez, P.A. Energy recovery in existing water networks: Towards greater sustainability. Water 2017, 9, 97. [CrossRef]

3. Colombo, A.F.; Karney, B.W. Energy and Costs of Leaky Pipes: Toward Comprehensive Picture. J. Water Resour. Plan. Manag. 2002, 128, 441-450. [CrossRef]

4. Ramos, H.M.; Vieira, F.; Covas, D.I.C. Energy efficiency in a water supply system: Energy consumption and $\mathrm{CO}_{2}$ emission. Water Sci. Eng. 2010, 3, 331-340. [CrossRef]

5. Gallagher, J.; Styles, D.; McNabola, A.; Williams, A.P.P. Life cycle environmental balance and greenhouse gas mitigation potential of micro-hydropower energy recovery in the water industry. J. Clean. Prod. 2015, 99, 152-159. [CrossRef]

6. Zema, D.A.; Nicotra, A.; Tamburino, V.; Zimbone, S.M. A simple method to evaluate the technical and economic feasibility of micro hydro power plants in existing irrigation systems. Renew. Energy 2016, 85, 498-506. [CrossRef]

7. Campisano, A.; Modica, C.; Vetrano, L. Calibration of Proportional Controllers for the RTC of Pressures to Reduce Leakage in Water Distribution Networks. J. Water Resour. Plan. Manag. 2012, 138, 377-384. [CrossRef]

8. Stokes, J.R.; Horvath, A.; Sturm, R. Water loss control using pressure management: Life-cycle energy and air emission effects. Environ. Sci. Technol. 2013, 47, 10771-10780. [CrossRef] [PubMed]

9. Schwaller, J.; van Zyl, J.E. Modeling the Pressure-Leakage Response of Water Distribution Systems Based on Individual Leak Behavior. J. Hydraul. Eng. 2014, 141, 04014089. [CrossRef]

10. Cabrera, E.; Pardo, M.A.; Cobacho, R.; Cabrera, E.J. Energy Audit of Water Networks. J. Water Resour. Plan. Manag. 2010, 136, 669-677. [CrossRef]

11. Eliades, D.G.; Polycarpou, M.M. Leakage fault detection in district metered areas of water distribution systems. J. Hydroinform. 2012, 14, 992. [CrossRef]

12. Khulief, Y.A.; Khalifa, A.; Mansour, R.B.; Habib, M.A. Acoustic Detection of Leaks in Water Pipelines Using Measurements inside Pipe. J. Pipeline Syst. Eng. Pract. 2012, 3, 47-54. [CrossRef]

13. Xu, Q.; Chen, Q.; Ma, J.; Blanckaert, K. Optimal pipe replacement strategy based on break rate prediction through genetic programming for water distribution network. J. Hydro-Environ. Res. 2013, 7, 134-140. [CrossRef]

14. Fontanazza, C.; Freni, G.; Loggia, G.; Notaro, V.; Puleo, V. Evaluation of the Water Scarcity Energy Cost for Users. Energies 2013, 6, 220-234. [CrossRef] 
15. Mushtaq, S.; Maraseni, T.N.; Reardon-Smith, K.; Bundschuh, J.; Jackson, T. Integrated assessment of water-energy-GHG emissions tradeoffs in an irrigated lucerne production system in eastern Australia. J. Clean. Prod. 2015, 103, 491-498. [CrossRef]

16. Filion, Y.R.; Maclean, H.L.; Asce, A.M.; Karney, B.W.; Asce, M. Life-Cycle Energy Analysis of a Water Distribution System. J. Infrastruct. Syst. 2004, 10, 120-130. [CrossRef]

17. Arriaga, M. Pump as turbine-A pico-hydro alternative in Lao People's Democratic Republic. Renew. Energy 2010, 35, 1109-1115. [CrossRef]

18. Ramos, H.M.; Mello, M.; De, P.K. Clean power in water supply systems as a sustainable solution: From planning to practical implementation. Water Sci. Technol. Water Supply 2010, 10, 39. [CrossRef]

19. Carravetta, A.; Antipodi, L.; Golia, U.; Fecarotta, O. Energy saving in a water supply network by coupling a pump and a Pump As Turbine (PAT) in a turbopump. Water 2017, 9, 62. [CrossRef]

20. Carravetta, A.; Fecarotta, O.; Golia, U.M.; La Rocca, M.; Martino, R.; Padulano, R.; Tucciarelli, T. Optimization of Osmotic Desalination Plants for Water Supply Networks. Water Resour. Manag. 2016, 30, 3965-3978. [CrossRef]

21. Fiuzat, A.A.; Akerkar, B.P. Power outputs of two stages of cross-flow turbine. J. Energy Eng. 1991, 117, 57-70. [CrossRef]

22. Sammartano, V.; Aricò, C.; Carravetta, A.; Fecarotta, O.; Tucciarelli, T. Banki-Michell optimal design by computational fluid dynamics testing and hydrodynamic analysis. Energies 2013, 6, 2362-2385. [CrossRef]

23. Sammartano, V.; Sinagra, M.; Filianoti, P.; Tucciarelli, T. A Banki-Michell turbine for in-line water supply systems. J. Hydraul. Res. 2017, 55, 686-694. [CrossRef]

24. Sopian, K.; Razak, J.A. Pico hydro: Clean power from small streams. In Proceedings of the 3rd World Scientific and Engineering Academy and Society International Conference on Renewable Energy Sources, Tenerife, Spain, 1-3 July 2009.

25. Gaius-obaseki, T. Hydropower opportunities in the water industry. Int. J. Environ. Sci. 2010, 1, $392-402$. [CrossRef]

26. Punys, P.; Dumbrauskas, A.; Kvaraciejus, A.; Vyciene, G. Tools for Small Hydropower Plant Resource Planning and Development: A Review of Technology and Applications. Energies 2011, 4, 1258-1277. [CrossRef]

27. Fecarotta, O.; McNabola, A. Optimal Location of Pump as Turbines (PATs) in Water Distribution Networks to Recover Energy and Reduce Leakage. Water Resour. Manag. 2017. [CrossRef]

28. Mcnabola, A.; Coughlan, P.; Williams, A.P. The technical and economic feasibility of energy recovery in water supply networks. In Proceedings of the International Conference on Renewable Energy and Power Quality, Las Palmas, Spain, 13-15 April 2011.

29. Carravetta, A.; Derakhshan Houreh, S.; Ramos, H.M. Introduction. In Pumps as Turbines: Fundamentals and Applications; Springer: Cham, Switzerland, 2018; pp. 3-26, ISBN 9783319675060.

30. Vilanova, M.R.N.; Balestieri, J.A.P. Modeling of hydraulic and energy efficiency indicators for water supply systems. Renew. Sustain. Energy Rev. 2015, 48, 540-557. [CrossRef]

31. Fecarotta, O.; Ramos, H.M.; Derakhshan, S.; Del Giudice, G.; Carravetta, A. Fine Tuning a PAT Hydropower Plant in a Water Supply Network to Improve System Effectiveness. J. Water Resour. Plan. Manag. 2018, 144. [CrossRef]

32. Pelli, T.; Hitz, H.U. Energy indicators and savings in water supply. J. Am. Water Work. Assoc. 2000, 92, 55-62. [CrossRef]

33. Emec, S.; Bilge, P.; Seliger, G. Design of production systems with hybrid energy and water generation for sustainable value creation. Clean Technol. Environ. Policy 2015, 17, 1807-1829. [CrossRef]

34. Gómez, E.; Cabrera, E.; Balaguer, M.; Soriano, J. Direct and indirect water supply: An energy assessment. Procedia Eng. 2015, 119, 1088-1097. [CrossRef]

35. Cabrera, E.; Gomez, E.; Cabrera, E., Jr.; Soriano, J.; Espert, V. Energy Assessment of Pressurized Water Systems. J. Water Resour. Plan. Manag. 2015, 141, 1-12. [CrossRef]

36. Carravetta, A.; Del Giudice, G.; Fecarotta, O.; Ramos, H.M. Energy Production in Water Distribution Networks: A PAT Design Strategy. Water Resour. Manag. 2012, 26, 3947-3959. [CrossRef]

37. Carravetta, A.; Fecarotta, O.; Martino, R.; Antipodi, L. PAT efficiency variation with design parameters. Procedia Eng. 2014, 70, 285-291. [CrossRef] 
38. Paish, O. Small hydro power: Technology and current status. Renew. Sustain. Energy Rev. 2002, 6, 537-556. [CrossRef]

39. Carravetta, A.; Del Giudice, G.; Fecarotta, O.; Ramos, H. PAT Design Strategy for Energy Recovery in Water Distribution Networks by Electrical Regulation. Energies 2013, 6, 411-424. [CrossRef]

40. Simpson, A.R.; Marchi, A. Evaluating the Approximation of the Affinity Laws and Improving the Efficiency Estimate for Variable Speed Pumps. J. Hydraul. Eng. 2013, 139, 1314-1317. [CrossRef]

41. Fecarotta, O.; Carravetta, A.; Ramos, H.M.; Martino, R. An improved affinity model to enhance variable operating strategy for pumps used as turbines. J. Hydraul. Res. 2016, 1686, 1-10. [CrossRef]

42. Carravetta, A.; Fecarotta, O.; Ramos, H.M. A new low-cost installation scheme of PATs for pico-hydropower to recover energy in residential areas. Renew. Energy 2018. [CrossRef]

43. Nautiyal, H.; Varun; Kumar, A. Reverse running pumps analytical, experimental and computational study: A review. Renew. Sustain. Energy Rev. 2010, 14, 2059-2067. [CrossRef]

44. Byrd, R.H.; Hribar, M.E.; Nocedal, J. An Interior Point Algorithm for Large-Scale Nonlinear Programming. SIAM J. Optim. 1999, 9, 877-900. [CrossRef]

45. Byrd, R.H.; Gilbert, J.C.; Nocedal, J. A trust region method based on interior point techniques for nonlinear programming. Math. Program. Ser. B 2000, 89, 149-185. [CrossRef]

(c) 2018 by the authors. Licensee MDPI, Basel, Switzerland. This article is an open access article distributed under the terms and conditions of the Creative Commons Attribution (CC BY) license (http://creativecommons.org/licenses/by/4.0/). 